\title{
Phthalate Metabolites in Maternal and Cord Plasma and Their Relations to Other Selected Endocrine Disruptors and Steroids
}

\author{
L. KOLATOROVA ${ }^{1}$, J. VITKU ${ }^{1}$, A. VAVROUS ${ }^{2,3}$, R. HAMPL ${ }^{1}$, K. ADAMCOVA ${ }^{4}$, \\ M. SIMKOVA ${ }^{1,5}$, A. PARIZEK ${ }^{4}$, L. STARKA ${ }^{1}$, M. DUSKOVA ${ }^{1}$
}

${ }^{1}$ Department of Steroids and Proteofactors, Institute of Endocrinology, Prague, Czech Republic, ${ }^{2}$ Unit for Chemical Safety of Products, National Institute of Public Health, Prague, Czech Republic, ${ }^{3}$ Department of Analytical Chemistry, Faculty of Science, Charles University, Prague, Czech Republic, ${ }^{4}$ Department of Obstetrics and Gynecology, First Faculty of Medicine, Charles University and General Teaching Hospital, Prague, Czech Republic, ${ }^{5}$ Faculty of Food and Biochemical Technology, University of Chemistry and Technology, Prague, Czech Republic

Received May 16, 2018

Accepted June 13, 2018

\section{Summary}

Endocrine disruptors (EDs) are known to have harmful effects on the human endocrine system; special effort is actually given to the exposure during pregnancy. Humans are usually exposed to a mixture of EDs, which may potentiate or antagonize each other, and the combined effect may be difficult to estimate. The main phthalate monoesters monoethyl-, mono- $n$-butyl-, monoisobutyl-, monobenzyl-, mono-(2-ethylhexyl)-, mono-(2ethyl-5-hydroxyhexyl)- and mono-(2-ethyl-5-oxohexyl) phthalate were determined in 18 maternal ( $37^{\text {th }}$ week of pregnancy) and cord plasma samples using liquid chromatography-tandem mass spectrometry. Previously determined levels of selected bisphenols, parabens and steroids were also considered in this study. In cord blood, there were significantly higher mono- $n$ butyl phthalate levels than in maternal blood $(p=0.043)$. The results of multiple regression models showed that maternal plasma phthalates were negatively associated with cord plasma androstenedione, testosterone and dehydroepiandrosterone and positively associated with estradiol and estriol. For estriol, a cumulative association was also observed for $\Sigma$ bisphenols. To the best of our knowledge, this is the first pilot study evaluating the effect of prenatal exposure by multiple EDs on newborn steroidogenesis. Our results confirmed phthalate accumulation in the fetal area and disruption of fetal steroidogenesis. This preliminary study highlights the negative impacts of in utero EDs exposure on fetal steroidogenesis.

\section{Key words}

Endocrine disruptor • Pregnancy • Phthalate • Bisphenol • Steroid

\section{Corresponding author}

L. Kolatorova-Sosvorova, Department of Steroids and Proteofactors, Institute of Endocrinology, Narodni 8, 11694 Prague, Czech Republic. E-mail: Ikolatorova@endo.cz

\section{Introduction}

The constant process of industrial development is closely related to environmental pollution and the presence of numerous chemicals in the water, soil and air. It is known that many chemicals may interfere with the human and animal endocrine systems and affect hormonal homeostasis; these substances have been termed endocrine disruptors (EDs) (Bergman et al. 2013, Diamanti-Kandarakis et al. 2009). Of the anthropogenic EDs, phthalates, bisphenols and parabens are among the most widespread. Various epidemiologic studies have associated ED exposure with adverse health outcomes in humans, predominantly disturbing the reproductive system in both men and women (Gore et al. 2015, Sifakis et al. 2017). Due to their structural similarity with estrogens, they interact with estrogen or androgen receptors and possess estrogenic or anti-androgenic effects (Kabir et al. 2015).

Phthalates are structurally diesters of phthalic acid (1,2-benzenedicarboxylic acid), a group of widely distributed industrial chemicals used in the manufacture of plastics, especially those made of polyvinyl chloride 
(PVC). They give plastics elasticity, with their content being directly proportional to the plasticity of products (Benjamin et al. 2017, Giulivo et al. 2016, Johns et al. 2015). Phthalates are only bound physically within the plastic polymer structure, and therefore changes in the environment (temperature, $\mathrm{pH}$, sunlight, pressure etc.) or contact with lipids or solvents can accelerate phthalate leaching or vaporizing from the plastic materials (Benjamin et al. 2017). In addition, low molecular weight phthalates (ester side-chain lengths, one to four carbons) such as diethylphthalate (DEP), di-n-butylphthalate (DnBP) and di-iso-butylphthalate (DiBP) are commonly used in cosmetics and personal care products, especially shampoo, soaps, nail polishes, perfumes and insect repellents, in pharmaceuticals as a component of tablet coatings (Bowman and Choudhury 2016, HernandezDiaz et al. 2009, Koo and Lee 2004), as well as in adhesives and industrial solvents (Phthalates 2008). High molecular weight phthalates (ester side-chain lengths, five or more carbons) such as di-(2-ethylhexyl) phthalate (DEHP) and benzyl-butyl-phthalate (BzBP) are usually used in PVC plastics employed in various consumer products, out of which they are leaching to food, water, air and soil (Benjamin et al. 2017, Bowman and Choudhury 2016, Giulivo et al. 2016, Johns et al. 2015, Phthalates 2008). Phthalates have been categorized as EDs and have been linked to various adverse health effects, particularly in relation to early life exposure (Bowman and Choudhury 2016, Katsikantami et al. 2016, Serrano et al. 2014). These substances are known to cross the human placenta (Mose et al. 2007), and multiple phthalates have been measured in human amniotic fluid and meconium (Arbuckle et al. 2016, Wittassek et al. 2009).

Humans are exposed to phthalates through ingestion, inhalation and dermal contact throughout their life including intrauterine development (Heudorf et al. 2007). Food is generally regarded as the major source of phthalate exposure. The variability of food contamination depends on the manufacturing process, food packaging, transportation, storage and many other factors (Giulivo et al. 2016). Following oral exposure, phthalate diesters are hydrolyzed by esterases to monoesters in the saliva or intestine. Monoesters may be absorbed in the body and cause harmful effects; they are the main detected metabolites of low molecular weight phthalates. The high molecular weight phthalate monoesters may be also further oxidized. Both phthalates are then conjugated as glucuronides and to a small extent sulfates, and excreted via the urine (Phthalates 2008). Systemic absorption of phthalates has also been observed after the dermal application of personal care products (Janjua et al. 2007, Witorsch and Thomas 2010) including various antistretch mark creams and ultrasound gel products (Messerlian et al. 2017). Some phthalate monoesters are products from more than one parent compound. The detailed metabolic degradation has been published by other authors (DeFlorio-Barker and Turyk 2016, Vrbík 2016). Human studies investigating the prenatal phthalate exposure to the reproductive effects have mostly been based on measurements of phthalate content in maternal urine. They have confirmed associations with various disorders such as decreased anogenital distance, testicular descent impairment (Swan et al. 2005), premature breast development in young girls (Colon et al. 2000), and disruption of folliculogenesis by altering ovarian and oocyte development (for review see Mallozzi et al. 2016).

Due to their leaching from plastics while chewing or sucking, the use of phthalates was restricted by the European Union (EU), and their use in foodstuffs was banned by Commission regulation (EU) 72/2002. Another important Commission regulation (EU) 84/2005 regulates the marketing and use of the phthalates DEHP, DBP and BBP in toys and childcare articles. DBP, BBP, DEHP and DiBP were classified as very dangerous substances in REACH - the Regulation on Registration, Evaluation, Authorisation and Restriction of Chemicals as part of the framework legislation on chemicals in the EU (Regulation (EC) No 1907/2006) (Ventrice et al. 2013).

Phthalates are not the only group of EDs known to leach from plastics. The estrogen active bisphenol A (BPA) is widely known and best studied of the bisphenols. It is used while processing the polycarbonate plastic materials and epoxy resins, and contained in consumer products like food and drink packaging, dental fillings, thermal receipts and others. Many recent studies have investigated BPA exposure during pregnancy, with BPA quantified in numerous maternal body fluids such as urine, milk and amniotic fluid, as well as in neonates and young children (Braun et al. 2011, Deceuninck et al. 2015, Ferguson et al. 2015, Shekhar et al. 2017). Though the European Commission is still tightening the regulations for BPA usage, it is often being fully or partly replaced by alternative bisphenols like bisphenol $\mathrm{S}$ (BPS), bisphenol F (BPF), bisphenol AF (BPAF) and others (Kolatorova et al. 2017, Kolatorova Sosvorova et al. 2017, Sartain and Hunt 2016), for which so far no 
regulation limiting their usage exists. The total bisphenol exposure may be therefore higher than when BPA is used alone (Sartain and Hunt 2016). Another group of ubiquitous EDs are parabens, antimicrobial preservatives used in the food, cosmetics and pharmaceutical industries. The most commonly-employed are methylparaben (MP) and propylparaben (PP); however ethyl- (EP), butyl- (BP) and benzylparaben (BenzylP) are also used, especially in combination (Karpuzoglu et al. 2013, Nowak et al. 2018). The increasing number of studies documenting the harmful activities of parabens led to various regulations issued by European Commission (Kolatorova et al. 2018, Nowak et al. 2018). Currently, the European Chemical Agency (ECHA 2017) is performing reproduction tests with the most widely used paraben - PP - and the results should be known in June 2019.

During pregnancy, the fetus is exposed to many factors from the environment due to the placental transfer of lipophilic substances (Barry and Anthony 2008). Throughout the life, women are exposed to various lipophilic EDs, which may accumulate in their fat stores. Among others, pregnancy leads to the redistribution of mother fat reserves, out of which EDs may be released to the circulation. They can subsequently pass through the placenta to the fetal compartment in quite high concentrations (Modena and Fieni 2004). Moreover, the immature fetal organism has only limited liver first-pass effect that makes EDs difficult to metabolize (Matsumoto et al. 2002). The allowed limits of EDs therefore do not fulfill their role as such during the intrauterine development and in addition the effects of various EDs may interfere and/or multiply their effects (Mantovani 2016, Matsumoto et al. 2002, Shekhar et al. 2017).

The present work is continuation of previously published study, where we examined the exposure of bisphenols and parabens during pregnancy and their relations to steroid changes (Kolatorova et al. 2018). In this study we focused mainly on the analytical measurements of phthalate metabolite levels in cord and maternal plasma, their transplacental transport and the influence of phthalates and other previously determined EDs on the levels of steroids within and between cord and maternal plasma.

\section{Material and Methods}

\section{Chemicals and reagents}

Chemicals and reagents used for the analysis of steroid hormones, bisphenols and parabens were described in detail in our previous work (Kolatorova et al. 2018).

Standards of monoethyl phthalate (MEP), monoisobutyl phthalate (MiBP), monobenzyl phthalate (MBzP), mono-(2-ethylhexyl) phthalate (MEHP) were from AccuStandard (New Haven, USA). Standards of mono- $n$-butyl phthalate (MnBP), mono-(2-ethyl-5hydroxyhexyl) phthalate (5-OH-MEHP), mono-(2-ethyl5-oxohexyl) phthalate (5-oxo-MEHP) were purchased from Sigma-Aldrich (St. Louis, MO, USA), as were acetonitrile, ammonium acetate, formic acid and acetic acid. The deuterated phthalates (D4-MEP, D4-MnBP, D4-MiBP， D4-MBzP， D4-MEHP， D4-5-OH-MEHP, D4-5-oxo-MEHP) were synthesized by Clearsynth (Budapest, Hungary). LC-MS grade methanol, water for chromatography and $\beta$-glucuronidase-aryl sulphatase were from Merck AG (Darmstadt, Germany).

\section{Study group}

The study involved 18 Czech healthy pregnant women with a physiological course of gravidity and single pregnancy, 15 gave birth spontaneously, 3 by caesarean section (November 2016 and January 2017), and all women were central-European origin. The mean age of pregnant women $(\mathrm{n}=18)$ was $34 \pm 3.7$ years and mean pregnancy weight gain was $15.2 \pm 4.4 \mathrm{~kg}$. Their mean BMI values before pregnancy and in the $37^{\text {th }}$ week of pregnancy were $21.9 \pm 2.9 \mathrm{~kg} / \mathrm{m}^{2}$ and $26.8 \pm 2.6 \mathrm{~kg} / \mathrm{m}^{2}$, respectively. None of the women used medications affecting steroidogenesis, have gestational diabetes, thyreopathy, risk of premature birth, intrauterine growth restriction or other pregnancy complications. Our study followed the Declaration of Helsinki (2000) of the World Medical Association. The protocol of the study was approved by the Ethical Commission of the General University Hospital in Prague. Informed written consent with the use of biological materials for research was obtained from all women involved in the study.

Women were examined during the $37^{\text {th }}$ week of pregnancy. They filled out an anonymous standardized questionnaire which included the data mentioned in Table 1. Thereafter, the cubital venous blood was collected (8-10 a.m.), the mixed cord blood was withdrawn at birth. Blood collected to K2EDTA tubes was immediately centrifuged $\left(5 \mathrm{~min}, 2,000 \mathrm{~g}, 4^{\circ} \mathrm{C}\right)$. To avoid contamination from collection devices, plasma was without delay transferred to the glass tubes and stored at $-20{ }^{\circ} \mathrm{C}$ until analysis. The sample preparation during 
Table 1. Characteristics of women $(n=18)$ during the $37^{\text {th }}$ week of pregnancy. The newborn sex and birth weight was noted after delivery.

\begin{tabular}{|c|c|}
\hline Characteristics & n (\%) \\
\hline \multicolumn{2}{|c|}{ Maternal age (years) } \\
\hline$<30$ & $2(11.1)$ \\
\hline $30-35$ & $10(55.6)$ \\
\hline$>35$ & $6(33.3)$ \\
\hline Mean $( \pm$ SD $)$ & $34(3.7)$ \\
\hline \multicolumn{2}{|c|}{ Pre-pregnancy BMI $\left(\mathrm{kg} / \mathrm{m}^{2}\right)$} \\
\hline$<20$ & $5(27.8)$ \\
\hline $20-25$ & $11(61.1)$ \\
\hline$>25$ & $2(11.1)$ \\
\hline Mean $( \pm \mathrm{SD})$ & $21.9(2.9)$ \\
\hline \multicolumn{2}{|l|}{ Parity } \\
\hline 1 & $5(27.8)$ \\
\hline 2 & $8(44.4)$ \\
\hline 3 & $4(22.2)$ \\
\hline 4 & $1(5.6)$ \\
\hline \multicolumn{2}{|l|}{ Education } \\
\hline High school & $5(27.8)$ \\
\hline University & $13(72.2)$ \\
\hline \multicolumn{2}{|c|}{ Monthly income (Czech crowns) } \\
\hline $10,000-25,000$ & $9(50.0)$ \\
\hline$>25,000$ & $9(50.0)$ \\
\hline \multicolumn{2}{|l|}{ Week of delivery } \\
\hline$<39$ & $0(0.0)$ \\
\hline $39-40$ & $17(94.4)$ \\
\hline$>41$ & $1(5.6)$ \\
\hline Mean $( \pm \mathrm{SD})$ & $39.8(0.5)$ \\
\hline \multicolumn{2}{|c|}{ Pregnancy weight gain (kg) } \\
\hline$<12$ & $3(16.7)$ \\
\hline $12-20$ & $13(72.2)$ \\
\hline$>20$ & $2(11.1)$ \\
\hline Mean $( \pm \mathrm{SD})$ & $15.2(4.4)$ \\
\hline \multicolumn{2}{|l|}{ Birth weight (kg) } \\
\hline$<3$ & $2(11.1)$ \\
\hline $3-4$ & $13(72.2)$ \\
\hline$>4$ & $3(16.7)$ \\
\hline Mean $( \pm \mathrm{SD})$ & $3.6(0.4)$ \\
\hline \multicolumn{2}{|l|}{ Marital status } \\
\hline Married & $11(61.1)$ \\
\hline Unmarried & 7 (38.9) \\
\hline \multicolumn{2}{|l|}{ Fetal sex } \\
\hline Male & $9(50.0)$ \\
\hline Female & $9(50.0)$ \\
\hline
\end{tabular}

the pre-analytical and analytical phases were performed with respect to the use of phthalate-, bisphenol- and paraben-free laboratory equipment. The way we have eliminated the contamination was described previously (Kolatorova Sosvorova et al. 2017). Possible false positive results of monoalkyl phthalates caused by contamination of the mobile phase were prevented by installing a chromatographic (trap) column between the HPLC mobile phase pump and the injector (see section Determination of analytes). A procedural blank sample was controlled with each batch of samples.

\section{Determination of analytes}

The plasma levels of unconjugated bisphenols (BPA, BPS, BPF, BPAF), parabens (MP, EP, PP, BP, BenzylP) and steroids (E1, E2, E3, cortisol, cortisone, DHEA, $7 \alpha-\mathrm{OH}-\mathrm{DHEA}, 7 \beta-\mathrm{OH}-\mathrm{DHEA}, 7$-oxo-DHEA, testosterone, androstenedione, pregnenolone, 17-hydroxy-pregnenolone and progesterone) were determined using two previously published validated liquid chromatography - tandem mass spectrometry (LC-MS/MS) methods. All the chromatography and mass spectrometry details can be found in the corresponding publications or their supplementaries (Kolatorova Sosvorova et al. 2017, Sosvorova et al. 2015, Vitku et al. 2016).

Phthalate metabolites (MEP, MnBP, MiBP, MBzP, MEHP, 5-OH-MEHP and 5-oxo-MEHP) were analyzed using enzymatic cleavage of glucuronide followed by ultra-high-performance liquid chromatography - electrospray ionization tandem mass spectrometry in a laboratory with external quality control: $500 \mu \mathrm{l}$ of plasma was spiked with $10 \mu \mathrm{l}$ of a solution containing isotopically labeled analyte analogs $(5 \mu \mathrm{g} / \mathrm{ml})$ and diluted with $100 \mu \mathrm{l}$ of ammonium acetate solution $(1 \mathrm{~mol} / \mathrm{l})$. $5 \mu \mathrm{l}$ of $\beta$-glucuronidase-aryl sulphatase solution was added and samples were incublated for $90 \mathrm{~min}$ at $37^{\circ} \mathrm{C}$. After adding $500 \mu \mathrm{l}$ of acetonitrile-acetic acid solution (50:1, v/v) followed by $300 \mu \mathrm{l}$ of aqueous magnesium sulfate solution $(25 \%, w / w)$, the enzymatic reaction was stopped, the enzyme precipitated out and two liquid phases formed. The resulting mixture was centrifuged to separate the phases. $3 \mu \mathrm{l}$ of the upper acetonitrile layer were injected into an ultra-high performance liquid chromatograph (UPLC) Infinity 1290 (Agilent, Santa Clara, CA, USA) connected to the Agilent 6490A triple stage quadrupole mass spectrometer with electrospray ionization (Agilent, Santa Clara, CA, USA). Chromatographic separation was performed using a Kinetex Phenyl-hexyl 100A $2.6 \mu \mathrm{m}$ 
(150 $2.1 \mathrm{~mm})$ column (Phenomenex, Torrance, CA, USA) maintained at $40{ }^{\circ} \mathrm{C}$. The Kinetex C18 100A $5 \mu \mathrm{m}$ $(50 \times 2.1 \mathrm{~mm})$ chromatographic column (Phenomenex, Torrance, CA, USA) was installed between the UPLC mobile phase pump and injector to avoid contamination from the mobile phase. The mobile phase gradient of demineralized water (A) and methanol (B) both containing $0.1 \%$ of formic acid was as follows: $0 \mathrm{~min}, 20 \% \mathrm{~B}$, $0.45 \mathrm{ml} / \mathrm{min}$; $1 \mathrm{~min}, 45 \% \mathrm{~B}, 0.4 \mathrm{ml} / \mathrm{min} ; 7 \mathrm{~min}, 55 \% \mathrm{~B}$,
$0.4 \mathrm{ml} / \mathrm{min}$; $9 \mathrm{~min}, 90 \% \mathrm{~B}, 0.4 \mathrm{ml} / \mathrm{min} ; 11 \mathrm{~min}, 90 \% \mathrm{~B}$, $0.5 \mathrm{ml} / \mathrm{min}$. Using this gradient, MiBP and MnBP were baseline separated. Validation parameters are given in Table 2. Other chromatography and mass spectrometry details were presented in Vrbík et al. (2016). The laboratory is accredited according to EN ISO/IEC 17025:2005 and regularly participates on external G-EQUAS external quality assessment scheme for phthalate metabolites.

Table 2. Retention times and validation parameters of phthalate metabolites.

\begin{tabular}{lccccccc}
\hline Phthalate & MEP & MiBP & MnBP & 5-oxo-MEHP & 5-OH-MEHP & MBzP & MEHP \\
\hline Retention time (min) & 3.7 & 6.7 & 7.0 & 7.6 & 7.7 & 8.2 & 10.1 \\
LOQ $*(\mathrm{ng} / \mathrm{ml})$ & 3.5 & 2.2 & 3 & 2.7 & 2.8 & 2.4 & 0.61 \\
Recoveries at $10 \mathrm{ng} / \mathrm{ml}(\%) * *$ & 92 & 101 & 116 & 108 & 90 & 98 & 104 \\
RSD at $10 \mathrm{ng} / \mathrm{ml}(\%)$ & 16 & 9.5 & 16 & 11 & 14 & 11 & 6.5 \\
\hline
\end{tabular}

LOQ - limit of quantification, RSD - relative standard deviation, MEP - monoethyl phthalate, MiBP - monoisobutyl phthalate, MnBP mono- $n$-butyl phthalate, 5-oxo-MEHP - mono-(2-ethyl-5-oxohexyl) phthalate, 5-OH-MEHP - mono-(2-ethyl-5-hydroxyhexyl) phthalate, MBzP - monobenzyl phthalate, MEHP - mono-(2-ethylhexyl) phthalate. * LOQs were determined as LOQ $=10 \mathrm{~s}_{a} / \mathrm{b}$, where $\mathrm{s}_{\mathrm{a}}$ is the standard deviation of the intercept and $b$ is the average slope in the repeated calibration curve analyses $(1$ to $1000 \mathrm{ng} / \mathrm{ml}, \mathrm{n}=6)$. ** Recoveries were not significantly different from $100 \%(p>0.34)$.

\section{Statistical analysis}

According to Hornung and Reed (1990), data under the limit of detection were replaced by LOQ $/ \sqrt{ } 2$. Afterwards, the Wilcoxon-Mann-Whitney test was used to evaluate differences in ED and steroid concentrations in cord plasma between male and female fetuses. Similarly, this test was used for comparison of the same set of analytes between group of fetuses born vaginally and group of fetuses born by caesarean section. ED and steroid concentrations in maternal plasma and cord plasma were compared by a sign test. Data were subsequently transformed by Box-Cox transformation and multiple linear regression analysis (backward stepwise selection) was performed to explore relations between each steroid as a dependent variable and EDs (phthalates, bisphenols, parabens) as predictors. Each model was adjusted for birth weight, maternal age, newborn gender and pregnancy weight gain. Birth weight, maternal age and pregnancy weight gain were modeled as continuous independent variables. The rest of covariates were modeled as dichotomous variables. All statistical testing was performed in Statgraphics Centurion XVI software from Statpoint Inc. (Warrenton, VA, USA).

\section{Results}

In maternal and cord plasma, the main conjugated phthalate monoesters were determined: monoethyl phthalate (MEP) - metabolite of DEP, mono$n$-butyl phthalate (MnBP) - a metabolite of DnBP, monoisobutyl phthalate (MiBP) - a metabolite of DiBP, monobenzyl phthalate (MBzP) - a metabolite of BzBP, and mono-(2-ethylhexyl) phthalate (MEHP), mono-(2ethyl-5-hydroxyhexyl) phthalate (5-OH-MEHP), and mono-(2-ethyl-5-oxohexyl) phthalate (5-oxo-MEHP), which are metabolites of DEHP. The other groups of unconjugated EDs as well as the levels of steroid hormones were determined as a part of our previous study (Kolatorova et al. 2018).

MiBP was detected in all maternal plasma samples and MnBP in $77.8 \%$ of the samples. MEP and MEHP were detected in two samples, and MBzP and 5-OH-MeHP in one sample only. 5-oxo-MEHP was not detected. Phthalate metabolites MiBP and MnBP were quantified in all cord plasma samples, MEP in six samples (33.3\%) and MEHP in 3 samples. MBzP, 5-OH-MeHP and 5-oxo-MeHP were not detected.

Because of low detection rate of several phthalates, the sum of phthalates ( $\Sigma$ phthalates) was 
calculated from all phthalates quantified. The medians of the most frequently detected phthalates together with previously quantified bisphenols and parabens as well as steroid hormone levels (Kolatorova et al. 2018) are shown in Table 3. Differences were observed in MnBP levels between maternal and cord plasma, with significantly higher MnBP levels in cord blood $(\mathrm{p}=0.043)$.

Table 3. Selected most frequently detected endocrine disruptors and steroid hormones in maternal and cord plasma (medians with lower and upper quartiles).

\begin{tabular}{|c|c|c|c|}
\hline Analyte & Maternal plasma (ng/ml) & Mixed cord plasma (ng/ml) & P-value \\
\hline$M E P$ & under LOQ & $3.50(3.50,4.36)$ & 0.800 \\
\hline$M i B P$ & $4.45(3.79,8.50)$ & $7.63(5.02,9.18)$ & 0.112 \\
\hline$M n B P$ & $4.37(2.87,5.93)$ & $5.15(3.97,6.90)$ & 0.043 \\
\hline Ephthalates & $12.9(10.6,18.4)$ & $16.4(12.2,19.4)$ & 0.191 \\
\hline$B P A$ & $0.049(0.020,0.088)$ & $0.098(0.013,0.242)$ & 0.093 \\
\hline Ebisphenols & $0.069(0.027,0.090)$ & $0.101(0.020,0.242)$ & 0.145 \\
\hline$M P$ & $0.014(0.014,0.850)$ & $0.059(0.014,0.603)$ & 1.000 \\
\hline$P P$ & $0.023(0.011,0.123)$ & $0.016(0.011,0.147)$ & 0.816 \\
\hline Eparabens & $0.060(0.032,1.080)$ & $0.121(0.026,0.744)$ & 0.862 \\
\hline E1 & $19.5(11.7,24.5)$ & $34.6(19.2,75.4)$ & $<0.001$ \\
\hline$E 2$ & $18.4(12.6,21.8)$ & $5.51(3.24,8.86)$ & $<0.001$ \\
\hline E3 & $8.3(7.57,10.5)$ & $71.9(54.6,95.7)$ & $<0.001$ \\
\hline Cortisol & $283(236,298)$ & $80(36,143)$ & 0.006 \\
\hline Cortisone & $84(68,104)$ & $292(220,341)$ & 0.006 \\
\hline DHEA & $1.57(0.95,2.31)$ & $2.3(1.36,3.86)$ & 1.000 \\
\hline $7 \alpha-O H-D H E A$ & $0.24(0.20,0.26)$ & $1.37(1.00,2.51)$ & 0.006 \\
\hline $7 \beta-O H-D H E A$ & $0.071(0.058,0.078)$ & $0.069(0.051,0.079)$ & 0.476 \\
\hline 7-oxo-DHEA & $0.033(0.017,0.038)$ & $0.091(0.006,0.194)$ & 0.006 \\
\hline Pregnenolone & $21.1(17.0,28.2)$ & $49.2(36.6,84.4)$ & 0.019 \\
\hline 17-OH-pregnenolone & $0.105(0.105,0.105)$ & $8.6(6.47,13.7)$ & 0.006 \\
\hline Testosterone & $0.50(0.33,0.70)$ & $0.13(0.08,0.17)$ & 0.006 \\
\hline Androstenedione & $0.62(0.30,1.05)$ & $0.44(0.31,0.75)$ & 0.610 \\
\hline Progesterone & $64(49,71)$ & $260(167,430)$ & 0.006 \\
\hline
\end{tabular}

P-values indicate statistical significance, with levels less than 0.05 highlighted in bold. Bisphenols, parabens and steroids were

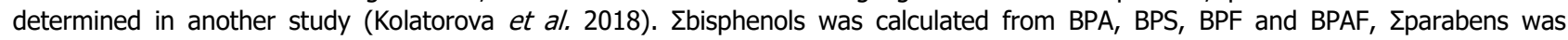
calculated from MP, EP, PP, BP and BenzylP.

Nine newborn boys and nine newborn girls were included in the study. Significantly higher levels were found in cord plasma from male newborns as follows: E2 $(p<0.0001)$, E3 $(p=0.034), 7 \alpha-O H-D H E A ~(p=0.009)$. We also investigated the influence of EDs on birth weight but found no association. There were also no differences found between the steroid hormone levels in caesarean and vaginal deliveries; however, only 3 caesarean sections were present in our study group. The levels of EDs in relation to the mother's education level were also compared, but no differences between mothers with university degree and high school education were observed. Interestingly, there were differences in the levels of PP between mothers with monthly income 10,000-25,000 CZK and >25,000 CZK, with mothers earning more than $25,000 \mathrm{CZK}$ per month having significantly higher levels of PP $(\mathrm{p}=0.037)$.

In order to investigate possible associations between phthalates and steroid hormones, multiple regression models were applied, but no associations with maternal phthalates and maternal steroids were observed.

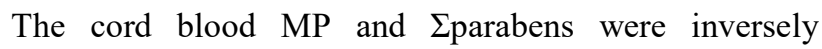


associated with cord blood testosterone levels. The adjusted regression coefficients $(\beta)$ with $95 \%$ confidence intervals $(\mathrm{CI})$ for the change in cord plasma steroids associated with interquartile range changes in cord plasma endocrine disruptor concentrations were as follows: $\beta$ : $-0.004 \mathrm{CI}$ : $(-0.007 ;-0.001), \mathrm{p}=0.012$ for $\mathrm{MP}$ and $\beta$ : -0.003 CI: $(-0.005 ;-0.001), \mathrm{p}=0.016$ for $\Sigma$ parabens.

The multiple regression models investigating the possible impact of maternal EDs on fetal steroid hormones showed that maternal blood levels of phthalates were positively associated with cord blood estrogens. Specifically, E2 was positively associated with $\mathrm{MnBp}$ and E3 with MnBP and $\Sigma$ phthalates. Maternal phthalates were negatively associated with several androgens (DHEA, androstenedione and testosterone). Maternal phthalates ( $\Sigma$ phthalates and MiBP) were also negatively associated with cord blood DHEA and androstenedione, while MnBP was negatively associated with testosterone.

As concern the previously measured levels of bisphenols and parabens, we observed several relations. A positive association was found for maternal इbisphenols and cord E3. Maternal BPA was also positively associated with $7 \beta-\mathrm{OH}-\mathrm{DHEA}$. Concerning parabens, opposite associations for MP and PP were observed - maternal MP was positively associated with cord blood E2 and testosterone, and maternal PP levels were conversely negatively associated with these steroids. For $\Sigma$ parabens, no associations for these mentioned steroids were found. MP was also positively associated with $7 \alpha-\mathrm{OH}-\mathrm{DHEA}$, and PP positively associated with cortisone. Sparabens were found to have positive associations with cortisone and $7 \alpha-\mathrm{OH}-\mathrm{DHEA}$. The results of the associations of maternal EDs and cord steroids are summarized in Table 4. The associations from all biological samples studied are schematically summarized in Table 5.

\section{Discussion}

Seven main phthalate metabolites, all known to act as EDs, were measured in maternal plasma at the $37^{\text {th }}$ week of pregnancy, and in cord blood of their newborns. These metabolites belong to the most abundant in human plasma (Frederiksen et al. 2010, Vrbík 2016). The data were taken together with previously quantified bisphenols and parabens and compared with levels of previously measured major sex hormones, corticoids and selected neuro- and immunomodulatory steroids, in order to evaluate the combined effect of these disruptors on steroid profiles. The main effort was focused on phthalates, the effect of which together with other disruptors has not yet been studied.

So far most authors have measured phthalate levels in maternal urine along with cord serum from their offspring. Since urine is a water intake-dependent fluid influenced by various factors, it is difficult to interpret the mother-newborn relations from the urinary data (Kato et al. 2003). In this study, we determined the phthalate levels directly from plasma (maternal and cord). Unlike urine, plasma reflects the phthalate metabolism in the mother body and shows the phthalate metabolites, which may be transferred to the fetus via placental transport. The reported plasma levels are generally much lower than urinary. Therefore, the analytes which are known to be less frequent in urine were expected to have even lower or zero frequency in plasma and were not included. The detection of quantified phthalate metabolites in the cord plasma should be explained only by the placental transport, because there was no possible contamination by exposure to plastic materials from medical service in the maternity hospital.

Until now, only few papers have dealt with measurements of phthalate metabolites in human serum or plasma. Since 2003, several studies have appeared concerning the detection of conjugated MEP, MBP and MEHP. Later, $\mathrm{MBzP}$ and other (altogether nine) phthalates were also determined in human serum using LC-MS (Kato et al. 2003, Silva et al. 2003). The levels found were on the order tens of $\mathrm{ng} / \mathrm{ml}$, which is in accordance with our measurements. The authors found detectable concentrations of MEP, MBP and MEHP in most serum samples tested. In 2008, a Swedish research group investigated the levels of phthalates in human breast milk, serum, blood and urine of 42 women after normal delivery using GC-MS. They determined levels of phthalate di-esters and mono-esters with a LOD in the low $\mathrm{ng} / \mathrm{ml}$ range, and detected the majority of phthalates of interest (Hogberg et al. 2008). In another study using LC-MS, only serum concentrations of oxidative phthalate metabolites were detected due to possible contamination by phthalate di- and mono-esters (Hines et al. 2009). In 2010 a Danish research group reported an LC-MS method for the determination of phthalate metabolites in urine, serum and seminal plasma (Frederiksen et al. 2010). They obtained similar results to ours, but they obtained better LODs (all below $1 \mathrm{ng} / \mathrm{ml}$ ). In 2014 Araki et al. (2014) measured the levels of MEHP in maternal and cord blood using GC-MS. They reported a median 


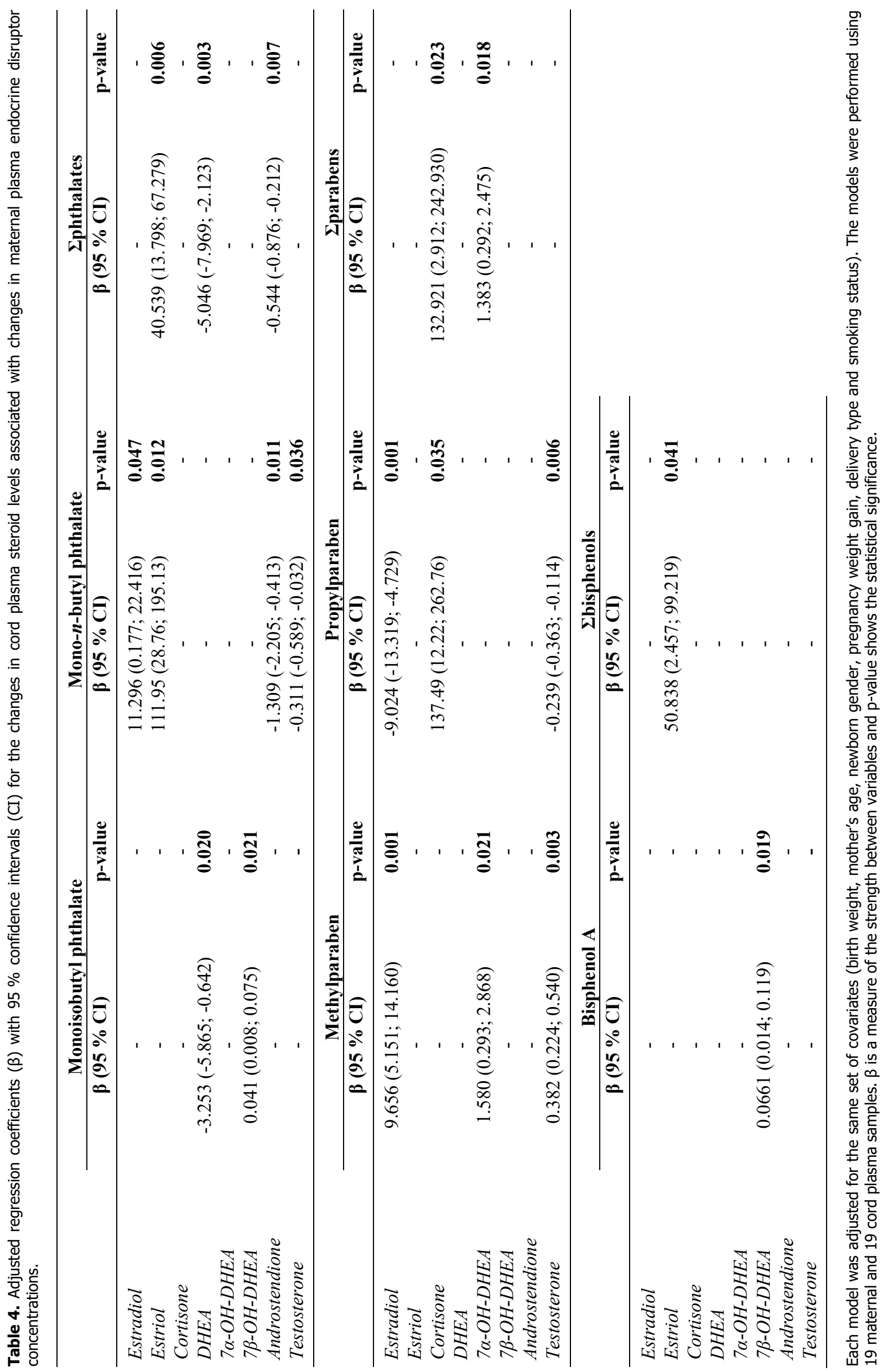


Table 5. The schematic results of multiple regression models showing the associations in different biological materials.

\begin{tabular}{|c|c|c|c|c|}
\hline Plasma material & Association & Phthalates - steroids & Bisphenols - steroids & Parabens - steroids \\
\hline Maternal - maternal & - & - & - & - \\
\hline \multirow{2}{*}{ Maternal-cord } & positive & $\begin{array}{l}\text { Estradiol (MnBP) } \\
\text { Estriol (MnBP, } \Sigma \text { phthalates) } \\
7 \beta-\mathrm{OH}-\mathrm{DHEA}(\mathrm{MiBP})\end{array}$ & $\begin{array}{l}7 \beta-O H-D H E A ~ B P A) \\
\text { Estriol ( } \Sigma \text { bisphenols) }\end{array}$ & 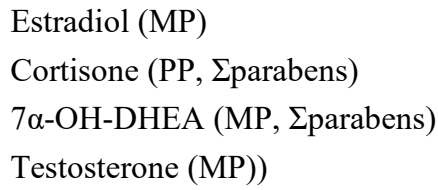 \\
\hline & negative & $\begin{array}{l}\text { DHEA (MiBP, } \Sigma \text { phthalates) } \\
\text { A-dione (MnBP, phthalates) } \\
\text { Testosterone (MnBP) }\end{array}$ & - & $\begin{array}{l}\text { Estradiol (PP) } \\
\text { Testosterone (PP) }\end{array}$ \\
\hline Cord - cord & negative & - & - & Testosterone (MP, इparabens) \\
\hline
\end{tabular}

A-dione - androstenedione.

maternal blood concentration of $10.4 \mathrm{ng} / \mathrm{ml}$, which is much higher than in our study. These higher levels may have been caused by a much higher MEHP exposure in the Japanese population. Even higher results of DEHP and MEHP (LOD $50 \mathrm{ng} / \mathrm{ml}$ with LOQ $100 \mathrm{ng} / \mathrm{ml}$ ) were found by other Japanese authors in plasma from healthy and autistic children by HPLC-UV (Kondolot et al. 2016). The plasma levels measured in children were much higher than the levels measured here in pregnant women and their offspring. This could have been caused by the high exposure of children to dangerous toys and other phthalate-releasing plastics.

The prenatal phase of human development is among the most active periods of life, and hormone signalization plays a significant role in fetal development (Hill et al. 2010, Paskova et al. 2014). All groups of EDs investigated in this study are capable of crossing the human placenta (Towers et al. 2015). The transfer of bisphenols and parabens was confirmed in our previous study (Kolatorova et al. 2018). The transplacental passage of phthalates in humans has also been documented by the finding of measurable concentrations of MEP, MBP and MEHP in human amniotic fluid (Silva et al. 2004) and by detectable levels of MBP, MEP and MEHP in umbilical cord plasma (Mose et al. 2007). Here we have also documented the accumulation of MnBP in the fetal compartment.

Brain development and fetal sexual differentiation are dependent on steroids produced in the fetal gonads. The levels of maternal estrogens are increased during pregnancy and therefore there is a mechanism protecting male fetuses from the maternal estrogen excess. The developing brain is protected from estrogens by alpha-fetoproteins that prevent estrogens from entering nerve cells. In male fetuses, the gonadal testosterone enters the cytoplasm where it is aromatized to E2, which binds to nuclear estrogen receptors and is responsible for the development of the male brain. During human gestation, estrogens are of maternal origin until about the $8^{\text {th }}$ week of pregnancy, when placenta production rises through the aromatization of fetal androgens (Adamcova et al. 2017). The significantly higher estrogen levels in the cord blood from male offspring found in our study may be caused by androgen aromatization by the placenta, similarly as in the study of Lin et al. (2011).

The estrogen and androgen balance is essential for the proper development of the fetus. Exposure to EDs with estrogenic and/or anti-androgenic activity may interfere with natural fetal development and cause various harmful effects (Kolatorova et al. 2017, Shekhar et al. 2017). Until recently, not many studies have focused on the complex effects of simultaneous prenatal exposures of the major groups of EDs on the fetal steroidogenesis. Many authors have investigated the effect of only one ED or group of structurally similar EDs (Araki et al. 2017, Araki et al. 2014, Liu et al. 2016). Several studies have examined phthalate exposure on androgen concentrations during human gestation and delivery, with the majority reporting a negative association between prenatal exposure to phthalates and free/total cord blood testosterone. This suggested the antivirilizing effect of phthalates, which persisted regardless of fetal sex (Lin et al. 2011, Main et al. 2006, Sathyanarayana et al. 2014, 
Sathyanarayana et al. 2017). The negative association between maternal MnBP and cord testosterone was observed in our study as well, in accordance with other authors (Araki et al. 2014, Lin et al. 2011, Main et al. 2006, Sathyanarayana et al. 2014, Sathyanarayana et al. 2017, Wen et al. 2017).

Recently, a further study has reported on the relation of urinary maternal phthalates to serum estrogens (E1, E2) in the first trimester of pregnancy, finding positive associations between estrogens (E1, E2) and phthalates (MBzP, MiBP, MEHP and MeOHP) and negative associations of free testosterone and several phthalates (Sathyanarayana et al. 2017). These results are in accordance with our findings, as well as with many animal and in vitro studies reporting phthalate estrogenicity. Of interest may be a persisting estrogenic effect of prenatal phthalate exposure (as measured in maternal urine) on the levels of plasma E2, testosterone and also progesterone, observed in children not only at birth, but even at 2, 5, 8 and 11 years of age (Wen et al. 2017).

Other authors have investigated associations between DEHP in maternal plasma (25-35 gestation week) and cord blood E2, testosterone and progesterone (Araki et al. 2014). They reported that increased maternal DEHP significantly decreased the progesterone and testosterone/E2 ratio in the cord blood. In 2017 these authors extended the number of steroids hormones measured to include DHEA, androstenedione, cortisol and cortisone (Araki et al. 2017), and found significant negative associations between maternal plasma DEHP and cord plasma androstenedione, cortisol and cortisone. In our study, however, we did not find any association of phthalates and either of the corticosteroids. Surprisingly, we found a positive association between cortisone and PP and $\Sigma$ parabens. The Japanese authors only determined the levels of DEHP, so our results and their measurements cannot be easily compared.

A few studies have also investigated the impact of phthalate exposure to DHEA or its sulfate in pubertal children of both sexes, but not in mother or their offspring; moreover, the results have been inconsistent (Ferguson et al. 2014, Mouritsen et al. 2013, Watkins et al. 2014). Our study and that of the Japanese group (Araki et al. 2017, Araki et al. 2014) were performed in the maternal and cord blood. The results revealed a negative association of phthalates and cord blood androstenedione, similar results were reported in the larger Japanese study (Araki et al. 2017). The negative associations of phthalates and offspring adrenal androgens are supported by the similar association with testosterone. These findings may confirm the antiandrogen effects of phthalates, which may be particularly important in male fetuses. We also studied associations between individual groups of EDs with 7-oxygenated metabolites of DHEA, believed to act as natural antiglucocorticoids with immunoprotective and neuromodulatory properties. Some positive associations were found between $7 \alpha-O H-D H E A$ and PP and $\Sigma$ parabens, and also between 7 3 -OH-DHEA with MiBP and BPA, respectively. These metabolites do not have androgenic activity, which may be reason for the opposite association as compared to DHEA. The altered levels of these metabolites may impair natural neurodevelopment, however no other information concerning this issue is currently available.

In our previous study we investigated the associations between bisphenols and parabens, and found no associations between maternal EDs and cord steroids (Kolatorova et al. 2018). In the current study we determined the levels of several phthalates, and we could thus assess the combined effect of multiple EDs. Investigating the phthalates, the multiple regression models taking into account the maternal EDs and cord steroids provided various associations. Overall, there were positive associations of maternal phthalates and cord estrogens (E2, E3) and negative associations between mother phthalates and cord androgens (androstenedione, testosterone, DHEA). These results are in accordance with the studies of Sathyanarayana et al. (2014, 2017). Prenatal exposure to phthalates has also been associated with adverse effects on neurodevelopment (Doherty et al. 2017). Because androgens play a crucial role in brain development, it is plausible that the anti-androgenic effect of phthalates and their capacity to affect fetal Leydig cell function and testosterone production and its conversion to E2 play an important role in the disruption of fetal neurodevelopment as well as sex organ development (Mallozzi et al. 2016). Concerning estrogens, in addition to phthalates we also found a positive association with bisphenols, which may emphasize the possible additive or synergic effect of these two groups of estrogen active EDs.

As concerns parabens, we confirmed our previously published negative associations with cord blood parabens and testosterone. On the other hand, different associations were found in the relations between 
maternal MP and PP and cord blood E2 and testosterone. Anyway, our results indicate that parabens play a less important role in the prenatal phase and that the risk of exposure to bisphenols and especially phthalates is higher. Phthalates influenced steroidogenesis in the offspring more than any other group of measured EDs. In some cases (E3), we were able to observe a possible cocktail effect of exposure to multiple EDs. It is clear that in evaluating the effect of EDs it is important to take into account the possible combined impacts of the multiple EDs that humans are exposed to.

We are aware of the limitation of our study consisting in the sample number. However, to the best of our knowledge, this is the first preliminary study evaluating the effects of prenatal exposure to multiple EDs on newborn steroidogenesis (cord blood). The future validation study is of interest. In the subsequent study, we intend to enlarge the number of pregnant women and their offspring.

\section{Conclusion}

In this pilot study, we found negative associations between maternal phthalates and cord androgens (androstenedione, testosterone, DHEA) and positive associations between maternal phthalates and cord estrogens (E2, E3). For estrogens, a similar association was also observed for bisphenols, underlining the possible additive or synergic effect of these two groups of estrogen active EDs. All the associations point to the possibility of disruption to newborn steroidogenesis, which may influence their subsequent lives. We also found significantly higher levels of MnBP in the cord blood compared to the maternal exposure. This indicates a possible accumulation of EDs in the fetal compartment. Our findings should encourage the population as well as international authorities to reduce ED exposure because of possible impacts on future generations.

\section{Conflict of Interest}

There is no conflict of interest.

\section{Acknowledgements}

This work was supported by the project MH CR 17-30528 A from the Czech Health Research Council and MH CZ - DRO (Institute of Endocrinology - EÚ, 00023761). The research team kindly acknowledges David W. Hardekopf for the proofreading.

\section{References}

ADAMCOVA K, KOLATOROVA L, CHLUPACOVA T, SIMKOVA M, JANDIKOVA H, PARIZEK A, STARKA L, DUSKOVA M: Changes to fetal steroidogenesis caused by maternal smoking. Physiol Res 66 (Suppl 3): S375-S386, 2017.

ARAKI A, MITSUI T, MIYASHITA C, NAKAJIMA T, NAITO H, ITO S, SASAKI S, CHO K, IKENO T, NONOMURA K, KISHI R: Association between maternal exposure to di(2-ethylhexyl) phthalate and reproductive hormone levels in fetal blood: the Hokkaido study on environment and children's health. PLoS One 9: e109039, 2014.

ARAKI A, MITSUI T, GOUDARZI H, NAKAJIMA T, MIYASHITA C, ITOH S, SASAKI S, CHO K, MORIYA K, SHINOHARA N, NONOMURA K, KISHI R: Prenatal di(2-ethylhexyl) phthalate exposure and disruption of adrenal androgens and glucocorticoids levels in cord blood: The Hokkaido Study. Sci Total Environ 581-582: 297-304, 2017.

ARBUCKLE TE, FISHER M, MACPHERSON S, LANG C, PROVENCHER G, LEBLANC A, HAUSER R, FEELEY M, AYOTTE P, NEISA A, RAMSAY T, TAWAGI G: Maternal and early life exposure to phthalates: The Plastics and Personal-care Products use in Pregnancy (P4) study. Sci Total Environ 551-552: 344-356, 2016.

BARRY JS, ANTHONY RV: The pregnant sheep as a model for human pregnancy. Theriogenology 69: 55-67, 2008.

BENJAMIN S, MASAI E, KAMIMURA N, TAKAHASHI K, ANDERSON RC, FAISAL PA: Phthalates impact human health: epidemiological evidences and plausible mechanism of action. J Hazard Mater 340: 360-383, 2017.

BERGMAN Å, HEINDEL JJ, JOBLING S, KIDD KA, ZOELLER RT, JOBLING SK: State of the science of endocrine disrupting chemicals 2012: an assessment of the state of the science of endocrine disruptors prepared by a group of experts for the United Nations Environment Programme and World Health Organization. World Health Organization, 2013. 
BOWMAN JD, CHOUDHURY M: Phthalates in neonatal health: friend or foe? J Dev Orig Health Dis 7: 652-664, 2016.

BRAUN JM, KALKBRENNER AE, CALAFAT AM, YOLTON K, YE X, DIETRICH KN, LANPHEAR BP: Impact of early-life bisphenol A exposure on behavior and executive function in children. Pediatrics 128: 873-882, 2011.

COLON I, CARO D, BOURDONY CJ, ROSARIO O: Identification of phthalate esters in the serum of young Puerto Rican girls with premature breast development. Environ Health Perspect 108: 895-900, 2000.

DECEUNINCK Y, BICHON E, MARCHAND P, BOQUIEN CY, LEGRAND A, BOSCHER C, ANTIGNAC JP, LE BIZEC B: Determination of bisphenol A and related substitutes/analogues in human breast milk using gas chromatography-tandem mass spectrometry. Anal Bioanal Chem 407: 2485-2497, 2015.

DEFLORIO-BARKER SA, TURYK ME: Associations between bone mineral density and urinary phthalate metabolites among post-menopausal women: a cross-sectional study of NHANES data 2005-2010. Int $J$ Environ Health Res 26: 326-345, 2016.

DIAMANTI-KANDARAKIS E, BOURGUIGNON JP, GIUDICE LC, HAUSER R, PRINS GS, SOTO AM, ZOELLER RT, GORE AC: Endocrine-disrupting chemicals: an Endocrine Society scientific statement. Endocr Rev 30: 293-342, 2009.

DOHERTY BT, ENGEL SM, BUCKLEY JP, SILVA MJ, CALAFAT AM, WOLFF MS: Prenatal phthalate biomarker concentrations and performance on the Bayley Scales of Infant Development-II in a population of young urban children. Environ Res 152: 51-58, 2017.

ECHA (European Chemicals Agency): Propyl 4-hydroxybenzoate substance evaluation decision, March 8, 2017. https://echa.europa.eu/information-on-chemicals/evaluation/community-rolling-action-plan/corap-table//dislist/details/0b0236e1807ea411

FERGUSON KK, PETERSON KE, LEE JM, MERCADO-GARCIA A, BLANK-GOLDENBERG C, TELLEZ-ROJO MM, MEEKER JD: Prenatal and peripubertal phthalates and bisphenol A in relation to sex hormones and puberty in boys. Reprod Toxicol 47: 70-76, 2014.

FERGUSON KK, MCELRATH TF, CANTONWINE DE, MUKHERJEE B, MEEKER JD: Phthalate metabolites and bisphenol-A in association with circulating angiogenic biomarkers across pregnancy. Placenta 36: 699-703, 2015.

FREDERIKSEN H, JORGENSEN N, ANDERSSON AM: Correlations between phthalate metabolites in urine, serum, and seminal plasma from young Danish men determined by isotope dilution liquid chromatography tandem mass spectrometry. J Anal Toxicol 34: 400-410, 2010.

GIULIVO M, LOPEZ DE ALDA M, CAPRI E, BARCELO D: Human exposure to endocrine disrupting compounds: their role in reproductive systems, metabolic syndrome and breast cancer. A review. Environ Res 151: 251-264, 2016.

GORE AC, CHAPPELL VA, FENTON SE, FLAWS JA, NADAL A, PRINS GS, TOPPARI J, ZOELLER RT: EDC-2: The Endocrine Society's second scientific statement on endocrine-disrupting chemicals. Endocr Rev 36: E1-E150, 2015.

HERNANDEZ-DIAZ S, MITCHELL AA, KELLEY KE, CALAFAT AM, HAUSER R: Medications as a potential source of exposure to phthalates in the U.S. population. Environ Health Perspect 117: 185-189, 2009.

HEUDORF U, MERSCH-SUNDERMANN V, ANGERER J: Phthalates: toxicology and exposure. Int J Hyg Environ Health 210: 623-634, 2007.

HILL M, PARIZEK A, JIRASEK JE, JIRKOVSKA M, VELIKOVA M, DUSKOVA M, KLIMKOVA M, PASKOVA A, ZIZKA Z, GERMANOVA A, KOUCKY M, KALOUSOVA M, STARKA L: Is maternal progesterone actually independent of the fetal steroids? Physiol Res 59: 211-224, 2010.

HINES EP, CALAFAT AM, SILVA MJ, MENDOLA P, FENTON SE: Concentrations of phthalate metabolites in milk, urine, saliva, and serum of lactating North Carolina women. Environ Health Perspect 117: 86-92, 2009.

HOGBERG J, HANBERG A, BERGLUND M, SKERFVING S, REMBERGER M, CALAFAT AM, FILIPSSON AF, JANSSON B, JOHANSSON N, APPELGREN M, HAKANSSON H: Phthalate diesters and their metabolites in human breast milk, blood or serum, and urine as biomarkers of exposure in vulnerable populations. Environ Health Perspect 116: 334-339, 2008. 
HORNUNG RW, REED LD: Estimation of average concentration in the presence of nondetectable values. Appl Occup Environ Hyg 5: 46-51, 1990.

JANJUA NR, MORTENSEN GK, ANDERSSON AM, KONGSHOJ B, SKAKKEBAEK NE, WULF HC: Systemic uptake of diethyl phthalate, dibutyl phthalate, and butyl paraben following whole-body topical application and reproductive and thyroid hormone levels in humans. Environ Sci Technol 41: 5564-5570, 2007.

JOHNS LE, COOPER GS, GALIZIA A, MEEKER JD: Exposure assessment issues in epidemiology studies of phthalates. Environ Int 85: 27-39, 2015.

KABIR ER, RAHMAN MS, RAHMAN I: A review on endocrine disruptors and their possible impacts on human health. Environ Toxicol Pharmacol 40: 241-258, 2015.

KARPUZOGLU E, HOLLADAY SD, GOGAL RM JR: Parabens: potential impact of low-affinity estrogen receptor binding chemicals on human health. J Toxicol Environ Health B Crit Rev 16: 321-335, 2013.

KATO K, SILVA MJ, BROCK JW, REIDY JA, MALEK NA, HODGE CC, NAKAZAWA H, NEEDHAM LL, BARR DB: Quantitative detection of nine phthalate metabolites in human serum using reversed-phase highperformance liquid chromatography-electrospray ionization-tandem mass spectrometry. J Anal Toxicol 27: 284-289, 2003.

KATSIKANTAMI I, SIFAKIS S, TZATZARAKIS MN, VAKONAKI E, KALANTZI OI, TSATSAKIS AM, RIZOS AK: A global assessment of phthalates burden and related links to health effects. Environ Int 97: 212-236, 2016.

KOLATOROVA L, DUSKOVA M, VITKU J, STARKA L: Prenatal exposure to bisphenols and parabens and impacts on human physiology. Physiol Res 66 (Suppl 3): S305-S315, 2017.

KOLATOROVA L, VITKU J, HAMPL R, ADAMCOVA K, SKODOVA T, SIMKOVA M, PARIZEK A, STARKA L, DUSKOVA M: Exposure to bisphenols and parabens during pregnancy and relations to steroid changes. Environ Res 163: 115-122, 2018.

KOLATOROVA SOSVOROVA L, CHLUPACOVA T, VITKU J, VLK M, HERACEK J, STARKA L, SAMAN D, SIMKOVA M, HAMPL R: Determination of selected bisphenols, parabens and estrogens in human plasma using LC-MS/MS. Talanta 174: 21-28, 2017.

KONDOLOT M, OZMERT EN, ASCI A, ERKEKOGLU P, OZTOP DB, GUMUS H, KOCER-GUMUSEL B, YURDAKOK K: Plasma phthalate and bisphenol A levels and oxidant-antioxidant status in autistic children. Environ Toxicol Pharmacol 43: 149-158, 2016.

KOO HJ, LEE BM: Estimated exposure to phthalates in cosmetics and risk assessment. $J$ Toxicol Environ Health A 67: 1901-1914, 2004.

LIN LC, WANG SL, CHANG YC, HUANG PC, CHENG JT, SU PH, LIAO PC: Associations between maternal phthalate exposure and cord sex hormones in human infants. Chemosphere 83: 1192-1199, 2011.

LIU C, XU X, ZHANG Y, LI W, HUO X: Associations between maternal phenolic exposure and cord sex hormones in male newborns. Hum Reprod 31: 648-656, 2016.

MAIN KM, MORTENSEN GK, KALEVA MM, BOISEN KA, DAMGAARD IN, CHELLAKOOTY M, SCHMIDT IM, SUOMI AM, VIRTANEN HE, PETERSEN DV, ANDERSSON AM, TOPPARI J, SKAKKEBAEK NE: Human breast milk contamination with phthalates and alterations of endogenous reproductive hormones in infants three months of age. Environ Health Perspect 114: 270-276, 2006.

MALLOZZI M, BORDI G, GARO C, CASERTA D: The effect of maternal exposure to endocrine disrupting chemicals on fetal and neonatal development: a review on the major concerns. Birth Defects Res C Embryo Today 108: 224-242, 2016.

MANTOVANI A: Endocrine disrupters and the safety of food chains. Horm Res Paediatr 86: 279-288, 2016.

MATSUMOTO J, YOKOTA $\mathrm{H}$, YUASA A: Developmental increases in rat hepatic microsomal UDP-glucuronosyltransferase activities toward xenoestrogens and decreases during pregnancy. Environ Health Perspect 110: 193-196, 2002.

MESSERLIAN C, MUSTIELES V, WYLIE BJ, FORD JB, KELLER M, YE X, CALAFAT AM, WILLIAMS PL, HAUSER R, ENVIRONMENT TEAM REPRODUCTIVE HEALTH STUDY: Ultrasound gel as an unrecognized source of exposure to phthalates and phenols among pregnant women undergoing routine scan. Int J Hyg Environ Health 220: 1285-1294, 2017. 
MODENA AB, FIENI S: Amniotic fluid dynamics. Acta Biomed 75 (Suppl 1): 11-13, 2004.

MOSE T, MORTENSEN GK, HEDEGAARD M, KNUDSEN LE: Phthalate monoesters in perfusate from a dual placenta perfusion system, the placenta tissue and umbilical cord blood. Reprod Toxicol 23: 83-91, 2007.

MOURITSEN A, FREDERIKSEN H, SORENSEN K, AKSGLAEDE L, HAGEN C, SKAKKEBAEK NE, MAIN KM, ANDERSSON AM, JUUL A: Urinary phthalates from 168 girls and boys measured twice a year during a 5-year period: associations with adrenal androgen levels and puberty. J Clin Endocrinol Metab 98: 3755-3764, 2013.

NOWAK K, RATAJCZAK-WRONA W, GORSKA M, JABLONSKA E: Parabens and their effects on the endocrine system. Mol Cell Endocrinol 474: 238-251, 2018.

PASKOVA A, PARIZEK A, HILL M, VELIKOVA M, KUBATOVA J, DUSKOVA M, ADAMCOVA K, KOUCKY M, SIMJAK P, CERNY A, STARKA L: Steroid metabolome in the umbilical cord: is it necessary to differentiate between arterial and venous blood? Physiol Res 63: 115-126, 2014.

PHTHALATES: Phthalates and Cumulative Risk Assessment: The Tasks Ahead. National Academies Press, Washington D.C., 2008.

SARTAIN CV, HUNT PA: An old culprit but a new story: bisphenol A and "NextGen" bisphenols. Fertil Steril 106: 820-826, 2016.

SATHYANARAYANA S, BARRETT E, BUTTS S, WANG C, SWAN SH: Phthalate exposure and reproductive hormone concentrations in pregnancy. Reproduction 147: 401-409, 2014.

SATHYANARAYANA S, BUTTS S, WANG C, BARRETT E, NGUYEN R, SCHWARTZ SM, HAALAND W, SWAN SH, TEAM T: Early prenatal phthalate exposure, sex steroid hormones, and birth outcomes. $J$ Clin Endocrinol Metab 102: 1870-1878, 2017.

SERRANO SE, BRAUN J, TRASANDE L, DILLS R, SATHYANARAYANA S: Phthalates and diet: a review of the food monitoring and epidemiology data. Environ Health 13: 43, 2014.

SHEKHAR S, SOOD S, SHOWKAT S, LITE C, CHANDRASEKHAR A, VAIRAMANI M, BARATHI S, SANTOSH W: Detection of phenolic endocrine disrupting chemicals (EDCs) from maternal blood plasma and amniotic fluid in Indian population. Gen Comp Endocrinol 241: 100-107, 2017.

SIFAKIS S, ANDROUTSOPOULOS VP, TSATSAKIS AM, SPANDIDOS DA: Human exposure to endocrine disrupting chemicals: effects on the male and female reproductive systems. Environ Toxicol Pharmacol 51: 56-70, 2017.

SILVA MJ, BARR DB, REIDY JA, KATO K, MALEK NA, HODGE CC, HURTZ D 3RD, CALAFAT AM, NEEDHAM LL, BROCK JW: Glucuronidation patterns of common urinary and serum monoester phthalate metabolites. Arch Toxicol 77: 561-567, 2003.

SILVA MJ, REIDY JA, HERBERT AR, PREAU JL JR, NEEDHAM LL, CALAFAT AM: Detection of phthalate metabolites in human amniotic fluid. Bull Environ Contam Toxicol 72: 1226-1231, 2004.

SOSVOROVA L, VITKU J, CHLUPACOVA T, MOHAPL M, HAMPL R: Determination of seven selected neuro- and immunomodulatory steroids in human cerebrospinal fluid and plasma. Steroids 98: 1-8, 2015.

SWAN SH, MAIN KM, LIU F, STEWART SL, KRUSE RL, CALAFAT AM, MAO CS, REDMON JB, TERNAND CL, SULLIVAN S, TEAGUE JL, STUDY FOR FUTURE FAMILIES RESEARCH TEAM: Decrease in anogenital distance among male infants with prenatal phthalate exposure. Environ Health Perspect 113: 1056-1061, 2005.

TOWERS CV, TERRY PD, LEWIS D, HOWARD B, CHAMBERS W, ARMISTEAD C, WEITZ B, PORTER S, BORMAN CJ, KENNEDY RC, CHEN J: Transplacental passage of antimicrobial paraben preservatives. J Expo Sci Environ Epidemiol 25: 604-607, 2015.

VENTRICE P, VENTRICE D, RUSSO E, DE SARRO G: Phthalates: European regulation, chemistry, pharmacokinetic and related toxicity. Environ Toxicol Pharmacol 36: 88-96, 2013.

VITKU J, HERACEK J, SOSVOROVA L, HAMPL R, CHLUPACOVA T, HILL M, SOBOTKA V, BICIKOVA M, STARKA L: Associations of bisphenol A and polychlorinated biphenyls with spermatogenesis and steroidogenesis in two biological fluids from men attending an infertility clinic. Environ Int 89-90: 166-173, 2016. 
VRBÍK K, VAVROUŠ A, PAVLOUŠKOVÁ J, MALÝ M, SVAČINA Š, PIECHA R, LACINOVÁ Z, MULLEROVÁ D, MATĚJKOVÁ D, MRÁZ M: Determination of phthalates and bisphenol A and their metabolites in different types of materials (in Czech). Klin Biochem Metab 24: 153-159, 2016.

WATKINS DJ, TELLEZ-ROJO MM, FERGUSON KK, LEE JM, SOLANO-GONZALEZ M, BLANKGOLDENBERG C, PETERSON KE, MEEKER JD: In utero and peripubertal exposure to phthalates and BPA in relation to female sexual maturation. Environ Res 134: 233-241, 2014.

WEN HJ, SIE L, SU PH, CHUANG CJ, CHEN HY, SUN CW, HUANG LH, HSIUNG CA, JULIE WANG SL: Prenatal and childhood exposure to phthalate diesters and sex steroid hormones in 2-, 5-, 8-, and 11-year-old children: a pilot study of the Taiwan Maternal and Infant Cohort Study. J Epidemiol 27: 516-523, 2017.

WITORSCH RJ, THOMAS JA: Personal care products and endocrine disruption: a critical review of the literature. Crit Rev Toxicol 40 (Suppl 3): 1-30, 2010.

WITTASSEK M, ANGERER J, KOLOSSA-GEHRING M, SCHAFER SD, KLOCKENBUSCH W, DOBLER L, GUNSEL AK, MULLER A, WIESMULLER GA: Fetal exposure to phthalates - a pilot study. Int $J$ Hyg Environ Health 212: 492-498, 2009. 